\title{
Calorimetric scrutiny of lipid binding by sticholysin II toxin mutants
}

\section{Jorge Alegre-Cebollada ${ }^{1}$, Michela Cunietti, Elías Herrero-Galán, José G. Gavilanes* and Álvaro Martínez del Pozo*.}

\author{
From the Departamento de Bioquímica y Biología Molecular I, Facultad de Ciencias \\ Químicas, Universidad Complutense de Madrid, 28040 Madrid, Spain. \\ ${ }^{1}$ Present address: Department of Biological Sciences, Columbia University, 1212 \\ Amsterdam Avenue, New York, NY 10027, U.S.A.
}

Running Title: Mechanism of pore formation

Keywords: actinoporin; equinatoxin; hemolytic toxin; ITC; lipid-binding

*Corresponding authors: JGG (ppgf@bbm1.ucm.es) and AMP (alvaro@bbm1.ucm.es). Phone: +34 913944158. Fax: +34 913944159.

Abbreviations used: ATR, attenuated total reflection; CD, circular dichroism; Ch, cholesterol; DOPC, 1,2-dioleoyl-sn-glycero-3-phosphocholine; EqtIl, equinatoxin II; FTIR, Fourier transform infrared spectroscopy; IPTG, isopropyl- $\beta$-Dthiogalactopyranoside; ITC, isothermal titration calorimetry; PFTs, pore-forming toxins; pl, isoelectric point; POC, phosphocholine; SDS, sodium dodecyl sulfate; SM, sphingomyelin; SPR, surface plasmon resonance; Stn, sticholysin; WT, wild-type.

The mechanisms by which pore-forming toxins are able to insert into lipid membranes are a subject of the highest interest in the field of lipid-protein interaction. Eight mutants affecting different regions of sticholysin II, a member of the pore-forming actinoporins family, have been produced and their hemolytic and lipidbinding properties compared to those of the wild-type protein. A thermodynamical approach to the mechanism of pore formation is also presented. Isothermal titration calorimetry experiments show that pore formation by sticholysin II is an enthalpydriven process that occurs with a high affinity constant $\left(1.7 \times 10^{8} \mathrm{M}^{-1}\right)$. Results suggest that conformational flexibility at the $\mathrm{N}$-terminus of the protein does not provide higher affinity for the membrane, even though it is necessary for correct pore 
formation. Membrane binding is achieved through two separate mechanisms, i.e. recognition of the lipid-water interface by a cluster of aromatic residues and additional specific interactions that include a phosphocholine-binding site. Thermodynamic parameters derived from titration experiments are discussed in terms of a putative model for pore formation. 


\section{Introduction}

Pore-forming toxins (PFTs) are water-soluble proteins that share the ability to interact with lipid membranes and form pores within them. The mechanisms that sustain such a dual behavior are currently being subject of a number of studies ${ }^{1}$. Actinoporins are the best characterized eukaryotic PFTs. They are produced by different sea anemone species as a single polypeptide chain of around 175 amino acids with an isoelectric point ( $\mathrm{pl}$ ) usually above $9^{2-4}$. In particular, equinatoxin II (EqtII) from Actinia equina and sticholysins I and II (Stnl and II) from Stichodactyla helianthus are the most thoroughly studied actinoporins. The 3D structures for both EqtIl and Stnll water-soluble states have been determined ${ }^{5-7}$. Both proteins are built on a basis of a $\beta$-sandwich fold composed of $10 \beta$-strands (Fig. 1A). Two $\alpha$-helices interact with both sides of the $\beta$-sandwich. One of them, the $\mathrm{N}$-terminal helix, is the largest part of the protein that can adopt a different structure without disrupting the fold of the $\beta$-sandwich ${ }^{5}$. Together with its amphiphilic character, this $\mathrm{N}$-terminal helix has been proposed to extend and be inserted into the membrane to form the pore walls ${ }^{8,9}$.

A variety of experimental approaches have been employed to study the mechanism of pore formation by actinoporins, which has enabled the proposal of a putative model of pore formation ${ }^{4}$ (Fig. 1B). The initial binding of soluble monomers (S) to the membrane ( $\mathrm{M}_{\mathrm{o}}$-state) would be accomplished by a cluster of aromatic residues $^{10,11}$, a phosphocholine (POC)-binding site ${ }^{7}$ and a basic stretch of amino acids $^{6}$. Then, dissociation of the N-terminal $\alpha$-helix and tetramerization would occur ${ }^{7}$, giving rise to the $\mathrm{M}_{1}$-state. Finally, the $\mathrm{N}$-terminal $\alpha$-helix would extend and lie parallel to the membrane $\left(M_{2}\right)^{12}$, prior to final pore formation $(P)$. However, this model is not free from some considerable uncertainties ${ }^{4}$. For instance, the possibility exists that soluble tetramers bind the membrane ${ }^{13}$ or even that the $M_{1}$ - and $M_{2}$-states are monomeric ${ }^{8}$. In addition, little is known about the relevance of specific residues in the different steps of the mechanism of pore formation. The main reason is that few mutagenesis studies have been carried out to date, and most of them were not designed to investigate the mechanism of pore formation, but the topology of membrane-bound states of actinoporins $s^{8,14}$ or the molecular determinants of sphingomyelin specificity ${ }^{15}$. 
The production and functional characterization of Stnll mutants with reduced hemolytic activity were sought in this work. Eight mutants, at different regions of the protein, were studied. Isothermal titration calorimetry (ITC) was employed to gain insight into the interaction of Stnll and its mutants with lipids, which has allowed an inspection on the thermodynamics of pore formation by a PFT.

\section{RESULTS}

\section{Mutants production and structural characterization}

There are four regions in actinoporin structure that are believed to be important for the mechanism of pore formation ${ }^{4}$. First, a cluster of aromatic residues and a POC-binding site would be responsible for the initial attachment to the membrane, together with some basic residues. Then, the $\mathrm{N}$-terminal region would adopt an $\alpha$-helical conformation and would penetrate into the membrane, forming the pore. In the present study, mutants covering those regions were prepared. F106L eliminates one aromatic residue from the cluster of aromatic residues, whereas Y111N affects one of the tyrosine residues located at the POC-binding site. A10P, S28P and A10P/S28P introduce proline residues in positions that may be important for the conformational changes necessary for $\mathrm{N}$-terminus extension and final pore formation. In particular, Ala-10 belongs to a region that is thought to become fully $\alpha$ helical in the $M_{1}-M_{2}$ stage (Fig. 1). Ser-28 forms part, together with Arg-29, of the peptide bond that is supposed to rotate to proceed through $M_{0}-M_{1}$ step ${ }^{7}$. In addition, Arg-29 belongs to one cluster of basic amino acids that has been postulated as an important motif due to its situation between the $\mathrm{N}$-terminus and the other lipidbinding regions ${ }^{9}$; therefore, R29Q mutant has also been produced. Finally, Lys-19 has been shown to be necessary for pore formation of a His-tagged version of Stn $11^{16}$, though its exact role in the mechanism of pore formation is unknown. Thus, Stnll K19E mutant has also been included in this study, together with the double mutant K19E/E23K.

All the mutant variants were purified to homogeneity from $E$. coli lysates (supplementary data) as described in the Experimental Procedures section. The purification protocol for the mutants was essentially that described for the wild-type protein ${ }^{17}$. K19E and R29Q mutants were not able to bind the carboximethylcellulose 
column at $\mathrm{pH} 7.8$, probably because of their decreased $\mathrm{pl}$, but both mutants were readily purified when the chromatography was carried out at $\mathrm{pH} 6.8$. Recovery yields for the mutant variants were similar to that for wild-type Stnll, with the notable exception of F106L (Table 1).

All the mutants showed far-UV CD spectra very similar to wild-type protein (supplementary data), suggesting that mutations did not alter the overall fold of Stnll. Significant differences were found only for $\mathrm{Y} 111 \mathrm{~N}$ mutant in the near-UV region (Fig.2). Such a difference may be explained by the removal of the Tyr residue, which absorbs in that region. In addition, Tyr-111 is located very near to some other aromatic residues (Tyr-135, Trp-110, Trp-114), whose contribution to the dichroism spectrum might be also altered by the mutation. In this regard, it has been shown that the differences found in the near-UV CD spectra between StnI and Stnll can be safely related to the extra Tyr present in StnI ${ }^{17}$. Infrared spectra of the proteins in the amide I and amide II regions $\left(1700-1500 \mathrm{~cm}^{-1}\right)$ were also indistinguishable (supplementary data), again suggesting that the structure of Stnll is preserved in the mutants.

Finally, the thermostability of the mutants was followed by CD spectroscopy. As can be seen in Fig. 3 and Table 1, the two-state thermal transition as well as the high thermostability of the wild-type protein are maintained in the mutants, with a maximum decrease of $8^{\circ} \mathrm{C}$ for the K19E/E23K double mutant and the remarkable fact that $\mathrm{Y} 111 \mathrm{~N}$ presents a $\mathrm{T}_{\mathrm{m}}$ value even higher than the wild-type protein. Altogether, these data are also in agreement with the preservation of the wild-type structure in the mutants.

\section{Hemolytic activity}

All the single mutations studied resulted in significantly less hemolytic proteins (Fig. 4, Table 1). R29Q and $\mathrm{Y} 111 \mathrm{~N}$ were especially affected, with only $3.0 \%$ and $0.6 \%$ of the wild-type activity. The introduction of prolines in positions 10 or 28 also led to a decrease in the activity of the mutants. Such a decrease was even higher for the double mutant A10P/S28P (4\% of activity). Interestingly, the substitution of Glu23 by Lys counterbalanced the K19E mutation, as the double mutant K19E/E23K was at least as active as the wild-type protein. 


\section{Isothermal titration calorimetry}

Isothermal titration calorimetry (ITC) is a very suitable technique to study the energetics of interactions between biological molecules ${ }^{18}$. In particular, ITC has been proven useful to discriminate among different mechanisms of peptide-lipid interactions $^{19}$. However, to our knowledge, there has not been any report on ITC applied to a pore-forming toxin interacting with lipid membranes so far.

SM:DOPC:Ch $(1: 1: 1)$ has been shown to be a very appropriate membrane composition for Stnll binding ${ }^{20}$. Injections of aliquots of these vesicles into the protein solution gave rise to negative power peaks (Fig. 5). The peaks were integrated in order to obtain the heat changes associated with each injection. The resulting binding isotherms corresponding to wild type Stnll and its mutants can be explained by a model in which the proteins bind to the membrane involving $n$ molecules of lipids (Fig. 5$)^{21}$. The values for the binding constant $K$, the enthalpy of binding $\Delta H$ and the parameter $n$ can be obtained from fitting of the results to the model outlined above (see Experimental Procedures section).

Stnll binding to SM:DOPC:Ch $(1: 1: 1)$ vesicles occurs with high affinity $(K=1.7$ $x 10^{8} \mathrm{M}^{-1}$ ) (Table 2). This value is strikingly similar to the one determined by surface plasmon resonance (SPR) for the actinoporin Eqtll binding to SM:DOPC $(1: 1)^{11,15}$. Such high affinity constants are characteristic of specific lipid-peptide interactions via complex formation ${ }^{19}$. ITC results also demonstrate that Stnll binding to lipid vesicles is an enthalpy-driven process (Table 2, Fig. 5). The enthalpy of binding was -44 $\mathrm{Kcal} / \mathrm{mol}$, a rather high value compared to other lipid binding peptides ${ }^{19}$ and proteins $^{22}$, although even higher enthalpy values have been determined in other systems such as apoA-I binding to egg $\mathrm{PC}^{23}$.

All the mutants studied also showed a negative enthalpy of binding (Fig. 5, Table 2). However, the exact values of $\Delta H$ and $\Delta S$ varied with respect to wild-type protein, suggesting that the mechanism of lipid-protein interaction is not preserved in the mutants ${ }^{18,24}$, which agrees with their different hemolytic activities (Fig. 4, Table 1). Regarding association constants, A10P, S28P and A10P/S28P bound with similar affinities to the vesicles. $K$ was slightly reduced for mutants $F 106 L$ and K19E, whereas $\mathrm{R} 29 \mathrm{Q}$ and $\mathrm{Y} 111 \mathrm{~N}$ variants showed $K$ values almost two orders of magnitude lower than wild-type Stnll (Table 2, Fig. 5). Interestingly, K19E/E23K shared similar binding parameters with wild-type protein. Thus, the substitution of 
Glu-23 by Lys again counterbalances the K19E mutation, in agreement with the hemolytic activities of the proteins (Fig. 4).

\section{Structural changes upon lipid binding}

Infrared spectroscopy is a highly convenient technique to study the structural changes associated to actinoporins lipid-binding ${ }^{9}$. Fig. $6 \mathrm{~A}$ shows the infrared spectrum of Stnll WT within SM:DOPC:Ch (1:1:1) membranes. Consistently with previous reports ${ }^{9,25}$, a higher absorbance at $1658 \mathrm{~cm}^{-1}$ is detected with respect to the lipid-free spectra (supplementary data). Concomitantly, a decrease in the absorbance at $1638 \mathrm{~cm}^{-1}$ happened. Such spectral changes reflect the increase in the $\alpha$-helical content of StnII ${ }^{9}$. Therefore, the change in the ratio between the absorbances at both frequencies is a good indicator of the extent of a-helix formation upon lipid binding. Most of the mutants showed an increase in this value that was equivalent to Stnll WT (Fig. 6B). However, the formation of a-helix in mutants introducing a proline at position 10 was clearly hampered (Fig. 6). In the case of $\mathrm{K} 19 \mathrm{E}$ and $\mathrm{Y} 111 \mathrm{~N}$, the formation of helical structure is slightly abolished (Fig. 6B). Regarding the polarization spectra, only $\mathrm{Y} 111 \mathrm{~N}$ mutant showed a marked decrease in the ability to induce changes in the lipid acyl chain orientation (Table 3). Such ability has been related to the formation of a toroidal pore by actinoporins ${ }^{26,27}$.

\section{Discussion}

Actinoporins pore formation mechanism is believed to involve at least four different steps (Fig. 1) ${ }^{4}$. However, no thermodynamic data about this process are currently available. In this work, ITC has been employed to gain insight into the thermodynamics of pore formation. Even though pore formation is a multistep process, binding isotherms are well adjusted to a simple model of binding (Fig. 5). Data presented in this report are compatible with a reversible interaction between Stnll and lipids characterized by a high affinity constant (Table 2). However, it has sometimes been considered that membrane penetration by actinoporins is an irreversible process ${ }^{28,29}$. In case the interaction was irreversible, binding isotherms should present very sharp transitions which would preclude the determination of affinity constants ${ }^{18}$. This seems not to be the case for Stnll (Fig. 5), in agreement 
with the fact that EqtIl is able to dissociate from DOPC:SM (1:1) membranes ${ }^{11,15}$, although with low rate constants. Interestingly, pore formation by Stnll is an enthalpy-driven process (Table 2). Then, it can be regarded as a new example of an atypical hydrophobic interaction guided by a favorable $\Delta H^{30,31}$. This indicates that the strength of interactions (e.g. Van der Waals, hydrogen bonds) between the lipids and the protein is higher than those existing with the solvent ${ }^{32}$. Furthermore, taking into consideration that $\Delta S$ is unfavorable (Table 2), a higher binding constant is predicted when lowering temperature, which agrees with the increase in actinoporins activity at low temperature ${ }^{33}$.

In this work, seven mutants with reduced hemolytic activity (Fig. 4) and showing no significant structural changes (supplementary data, Fig. 2, and Fig. 3) have been produced and purified to homogeneity (supplementary data and Table 1). Mutations have been introduced at positions presumably involved in different steps of pore formation. In particular, the current putative model for pore formation by actinoporins states that initial binding and final pore formation are mediated by different protein regions ${ }^{11}$. The results presented in Table 2 support the idea that the $\mathrm{N}$-terminus is not needed for membrane recognition, since the $\mathrm{N}$-terminal mutants bind to the vesicles with approximately the same affinity than the wild-type protein. Only K19E mutant showed a slightly lower affinity constant. On the contrary, mutations affecting the clusters of aromatic or basic residues, or the POC-binding site, resulted in protein variants with reduced affinity for lipids.

Regarding the mutations located at the putative lipid-binding regions, two different behaviors were detected. Whereas R29Q and $\mathrm{Y} 111 \mathrm{~N}$ present a marked decrease in the association constant $K, \mathrm{~F} 106 \mathrm{~L}$ showed an affinity constant only $\sim 3$ times lower than wild-type. Phe-106 is one of the aromatic residues presumably involved in the interaction with the lipid-water interface ${ }^{16}$. In fact, its relative binding and hemolytic activities are coincident (Table 2), suggesting that the decrease in the hemolytic activity of this mutant may be explained only by a defective lipid binding. In agreement with this fact, $\mathrm{F} 106 \mathrm{~L}$ seemed to retain the ability to extend the $\mathrm{N}$-terminal a-helix (Fig. 6B) and alter lipid acyl chain orientation (Table 3). Considering the interfacial scale developed by Wimley and White ${ }^{34}$, a Phe $\rightarrow$ Leu mutation within the lipid-water interface should imply a $+0.57 \mathrm{Kcal} / \mathrm{mol}$ variation in the free energy of the system. This value matches with that of $+0.5 \mathrm{Kcal} / \mathrm{mol}$ derived from the calculated constants (Table 2), which supports the idea of Phe-106 exclusively contributing to 
the lipid-water interface recognition. A clearly different scenario is found for $\mathrm{Y} 111 \mathrm{~N}$ and $\mathrm{R} 29 \mathrm{Q}$ mutants. The experimentally derived variations in $\Delta G$ are $+2.5 \mathrm{Kcal} / \mathrm{mol}$ and $+2.4 \mathrm{Kcal} / \mathrm{mol}$, respectively, far from the values of $+1.4 \mathrm{Kcal} / \mathrm{mol}$ and -0.23 $\mathrm{Kcal} / \mathrm{mol}$ predicted by the interfacial scale ${ }^{34}$. Therefore, Tyr-111 and Arg-29 might be involved in additional interactions different from interface affinity. In this regard, it is interesting to note that the theoretical $\Delta G$ of partitioning residues 99 to 119 of StnII ${ }^{29}$, where the cluster of aromatic residues is located, is -5.0 to $-7.6 \mathrm{Kcal} / \mathrm{mol}$ (depending on the protonation state considered for the aspartates), different from the experimental value of $-9.1 \mathrm{Kcal} / \mathrm{mol}$ (Table 2). Therefore, additional interactions apart from the location of the aromatic stretch of residues at the lipid-water interface must occur. In particular, Tyr-111 has been shown to belong to a POC-binding site described by X-ray crystallography ${ }^{7}$. Taking into account that POC is the polar headgroup of the lipids sensitive to actinoporins ${ }^{35}$, the POC-binding site was proposed to be a phospholipid-binding region ${ }^{7}$. Thus, the ITC results for $\mathrm{Y} 111 \mathrm{~N}$ reported herein reinforce this idea. On the contrary, Arg-29 has not been related to any specific interaction with the membrane so far. Thus, the present results are the first indication of such an interaction. It was suggested that a rotation between Ser28 and Arg-29 may occur after membrane binding ${ }^{7}$. In addition, Arg-29 and Phe-106 probably establish cation- $\pi$ interactions ${ }^{16}$. Therefore, Arg-29 seems to be a crucial residue in the mechanism of pore formation, since it may participate in both membrane recognition and conformational changes leading to pore formation. The equivalent position in Eqtll has also been shown to be important for the activity of the protein $^{14}$.

For $\mathrm{Y} 111 \mathrm{~N}$ and $\mathrm{R} 29 \mathrm{Q}$ mutants, there is not a match between relative binding and hemolytic activities (Table 2). For $\mathrm{Y} 111 \mathrm{~N}$, the lower hemolytic activity cannot be explained only by defective lipid binding, suggesting that additional steps may be hampered. Accordingly, a-helix formation upon lipid binding is slightly reduced in this mutant (Fig. 6B) and its ability to change the orientation of lipid acyl chains is also hindered (Table 3). This suggests that the POC-binding site might be involved in the reorientation of lipids in order to establish a toroidal pore. Noteworthy, recently it was suggested that Tyr-113 in EqtIl (equivalent to Tyr-111 in StnlI) may be needed for the specific recognition of $S M^{15}$. Different to $\mathrm{Y} 111 \mathrm{~N}, \mathrm{R} 29 \mathrm{Q}$ has a higher hemolytic activity than would be expected from its affinity for lipids, suggesting that the glutamine at position 29 may facilitate the process of pore formation once the protein 
is bound to the membrane, which is in agreement with the infrared data (Fig. $6 B$ and Table 3).

Overall, these results suggest the importance of residues Arg-29, Phe-106 and $\mathrm{Y} 111 \mathrm{~N}$ in agreement with their high degree of conservation among the actinoporin family. Arg-29 and Tyr-111 are $100 \%$ conserved, whereas Phe-106 is substituted by a tyrosine residue in only some of them ${ }^{4}$.

Regarding the mutations at the N-terminus, A10P, S28P and A10P/S28P show that conformational stiffness at this region may hamper pore formation, which agrees with previous reports ${ }^{11,36}$. However, their ability to bind lipids is preserved (Table 2). Only a very slight decrease in $K$ is detected for S28P mutant, which may explain by itself its loss of hemolytic activity (Table 2). Then, these proline mutants suggest that conformational changes at the $\mathrm{N}$-terminus that are necessary for pore formation, most probably a-helix extension ${ }^{9}$ (Fig. 6), may not provide with higher affinity for the membrane. In other words, the initial interaction of Stnll with lipids would be strong enough for efficient pore formation upon appropriate conformational changes. This result agrees with the behavior of a double cysteine mutant of Eqtll. When oxidized, this mutant is not able to dissociate the N-terminus from the central $\beta$-sandwich. However, its affinity for lipids is only slightly reduced ${ }^{11}$. As noted above, Ser-28 forms part of the peptide bond that is supposed to rotate after lipid binding. Ala-10 is located in the region thought to become $\alpha$-helical in the last steps of pore formation (Fig. 1) $)^{9}$. The hemolytic activity of A10P/S28P is markedly reduced with respect to single mutants, suggesting that Ala-10 and Ser-28 are indeed participating in different stages of the mechanism of pore formation. Ala-10 seems to be more sensitive to proline substitution than Ser-28, according to the hemolytic activities of the single mutants (Table 2), which agrees with the higher degree of conservation found for Ala-10 4 .

In a binding reaction, $\Delta H$ mainly reflects the strength of interactions, whereas $\Delta S$ results from two contributions, i.e. the changes in solvation entropy and conformational entropy ${ }^{32}$. Even though the application of these concepts to the lipidprotein interaction is not clear-cut ${ }^{19}$, variations in $\Delta H$ and $\Delta S$ may offer valuable information about the mechanism of binding of the mutants. For instance, helix formation in a membrane environment is characterized by a favorable enthalpy change and an unfavorable entropy change ${ }^{37}$. Thus, the enthalpy and entropy changes associated with A10P and A10P/S28P binding to lipids (Table 2) might be 
explained by a deficient $\alpha$-helix formation. This is in excellent agreement with the results from infrared spectroscopy (Fig. 6B). Such trends are not observed in S28P variant, suggesting that this mutant would retain the ability to extend the $\mathrm{N}$-terminal a-helix. Remarkably, results with K19E mutant suggest that a-helix formation might be also altered in this mutant (Fig. $6 B$ and Table 2). This may explain the fact that the relative hemolytic activity of the mutant is lower than the relative binding to lipids (Table 2). In particular, the introduction of a glutamate at position 19 might destabilize the $\mathrm{N}$-terminal helix through electrostatic repulsion with other near negative groups like Asp-18, Glu-23 or Glu-24. The fact that K19E/E23K double mutant is as active as wild-type reinforces that idea. Interestingly, K19E/E23K binding to lipids is characterized by similar $\Delta H$ and $\Delta S$ to the wild-type, which suggests that the mechanism of binding of both proteins is the same. Unfortunately, E23K could not be produced by using the same expression system than for the other mutants (data not shown). Glu-23 seems to be interacting with the N-terminal positive charge in the water-soluble state (Fig. 1). The charge reversal introduced in E23K mutant would not allow such an interaction. This may destabilize the $\mathrm{N}$ terminus, causing the mutant not to be properly produced by $E$. coli cells. In the K19E/E23K double mutant, the newly introduced Glu at position 19 may accomplish the function of the removed Glu-23, according to the situation of residue 19 in the Stnll water-soluble three-dimensional structure (Fig. 1). The $8^{\circ} \mathrm{C}$ decrease in the thermostability of K19E/E23K mutant (Table 1) may indicate that this new interaction is not as effective as in wild-type Stnll.

To conclude with, this study sustains proposed functional roles for the different regions of actinoporins. In addition, it reveals that other interactions apart from the interfacial location of the cluster of aromatic residues must occur. One of such interactions involves the POC-binding site, as demonstrated for $\mathrm{Y} 111 \mathrm{~N}$ mutant. Furthermore, the results obtained for the proline mutants at the $\mathrm{N}$-terminus indicate that the last steps of pore formation do not provide additional affinity for the membrane. In addition, this study shows that the application of ITC to pore-forming toxins offers very valuable information for this extremely interesting family of proteins.

\section{Experimental procedures}




\section{Materials}

Brain sphingomyelin (SM), 1,2-dioleoyl-sn-glycero-3-phosphocholine (DOPC), and cholesterol (Ch) were obtained from Avanti Polar Lipids (Alabaster, AL). All other reagents used were of the highest purity available and were purchased from regular commercial sources.

\section{Proteins production}

Wild-type (WT) Stnll and its mutants were produced in an E. coli expression system that has been described before for wild-type Stn $\mathrm{II}^{17}$. The cDNAs coding for K19E, F106L, and Y111N mutants were obtained as described elsewhere ${ }^{16}$. Mutants A10P, S28P, R29Q, A10P/S28P, and K19E/E23K, were prepared by the overlap extension mutagenesis method ${ }^{38}$. Inserts from the final expression plasmids were sequenced to assure that no mutations other than expected were present. DNA manipulations were performed according to standard procedures ${ }^{38}$.

Protein production in RB791 E. coli cells was induced at $\mathrm{OD}_{600}=1.0$ with 1 mM IPTG for four hours at $37^{\circ} \mathrm{C}$. Then, cells were harvested and cellular pellet was subjected to seven pulses of sonication $(20 \mathrm{Kc}, 1 \mathrm{~min})$ in an ice bath. $50 \mathrm{mM}$ Tris buffer including 1\% Tween 20 was employed; $\mathrm{pH}$ was set at 6.8 or 7.8 depending on the theoretical pl of the mutant. The soluble fraction was loaded onto a carboximethylcellulose CM52 (Whatman, Brentford, England) and eluted with a 0 $0.5 \mathrm{M} \mathrm{NaCl}(0-0.3 \mathrm{M} \mathrm{NaCl}$ when purifying mutants with decreased pl) gradient in $50 \mathrm{mM}$ Tris buffer after appropriate washing steps. Homogeneous purified fractions of all the mutants could be obtained by this procedure, as checked by $0.1 \%$ SDS (sodium dodecyl sulfate) - 15\% polyacrylamide gel electrophoresis.

\section{Structural characterization}

Amino acid analyses after acid hydrolysis of the proteins $(5.7 \mathrm{M} \mathrm{HCl}, 24$ hours, $110^{\circ} \mathrm{C}$ ) were performed on a Biochrom 20 (Pharmacia, Uppsala, Swedden). The results were in agreement with those expected and were used to estimate extinction coefficients (Table 1) and protein concentrations for each mutant. 
Absorbance measurements were carried out on an Uvikon 930 spectrophotometer (Kontron Instruments, Milano, Italy). To record circular dichroism (CD) spectra, proteins were dissolved in $15 \mathrm{mM}$ Mops buffer, $\mathrm{pH} 7.5$, containing 0.1 $\mathrm{M} \mathrm{NaCl}(0.2-1 \mathrm{mg} / \mathrm{mL}$ protein concentration). CD spectra were obtained on a Jasco 715 spectropolarimeter (Easton, MD) at $50 \mathrm{~nm} / \mathrm{min}$ scanning speed. $0.1-\mathrm{cm}$-optical path cells were employed in the $200-250 \mathrm{~nm}$ region, whereas 1-cm-optical path cells were used in the $250-350 \mathrm{~nm}$ range. At least, four spectra were averaged to obtain the final spectrum. CD measurements were also employed to study the thermal stability of the mutants, as described for wild type protein ${ }^{39}$. At neutral $\mathrm{pH}$, thermal denaturation of Stnll occurs simultaneously with a fast aggregation, which can be monitored as optical path clarification (aggregates settling) by CD measurements at $218 \mathrm{~nm}$. Temperature scans were carried out at $0.5^{\circ} \mathrm{C} / \mathrm{min}$ rate. Results are expressed as percentages of the total $C D$ variation versus temperature. $T_{m}$ corresponds to the temperature at the midpoint of the monophasic thermal transition.

Fourier transform infrared (FTIR) spectra were acquired on a Bruker IFS 66/S FTIR spectrophotometer (Ettlingen, Germany). The BioATR I attenuated total reflection (ATR) device (Bruker) containing a germanium plate as the internal reflection element was employed ( $45^{\circ}$ aperture angle, 5 internal reflections). Spectra were obtained at a resolution of $2 \mathrm{~cm}^{-1}$ with an aperture of $9 \mathrm{~mm}$ in a single-sided, forward-backward mode. Dry air was used to purge the optic and the sample compartments (15 L/min). Two levels of zero filling of the interferogram were performed before Fourier transform. The germanium crystal was washed in Alcojet (Alconox, White Plains, NY) and rinsed with distilled water. $25 \mu \mathrm{L}$ of the protein solution in water $(1 \mathrm{mg} / \mathrm{mL})$ were spread on the Ge plate and gently evaporated under a $\mathrm{N}_{2}$ flow to obtain a thin film. In the case of protein/lipid samples, an appropriate amount of protein $(20$ - $60 \mu \mathrm{g})$ was incubated for 30 minutes in water with $70 \mathrm{nmol}$ of SM:DOPC:Ch (1:1:1) vesicles prepared as explained below. Then, samples were centrifuged at $164,000 \mathrm{~g}$ for 3 hours at $4^{\circ} \mathrm{C}$ in a 42.2 Ti rotor from Beckman (Fullerton, CA). Pellets were suspended in $10 \mu \mathrm{L}$ of water and deposited on the Ge plate as above. Measurements were carried out at room temperature. Resulting spectra were corrected for atmospheric water absorption lines as described before ${ }^{40}$ and smoothed by apodization of its Fourier transform by the Fourier transform of a $4 \mathrm{~cm}^{-1}$ Gaussian line shape. Polarized light spectra were employed to estimate molecular orientations as described before ${ }^{20}$. For lipid/protein 
spectra, the ratio between the lipid ester band $\left(1762-1716 \mathrm{~cm}^{-1}\right)$ and amide I band $\left(1700-1600 \mathrm{~cm}^{-1}\right)$ areas was approximately kept constant and equal to $6-8$.

\section{Hemolysis assay}

Hemolysis assays were performed in 96 -multiwell plates as described ${ }^{17}$. Briefly, erythrocytes from heparinized sheep blood were washed in $10 \mathrm{mM}$ Tris buffer, $\mathrm{pH} 7.4$, containing $0.145 \mathrm{M} \mathrm{NaCl}$, to a final $\mathrm{OD}_{620}$ of 0.5 when lysed by mixing equal volumes of the cell suspension and $0.1 \% \mathrm{Na}_{2} \mathrm{CO}_{3}(\mathrm{w} / \mathrm{v})$. The hemolysis was followed as a decrease in the $\mathrm{OD}_{620}$ after adding the erythrocyte suspension to twofold serial dilutions of the proteins. An Expert 96 microplate reader (Asys Hitech, $\mathrm{GmbH}$, Eugendorf, Austria) was employed to measure the $\mathrm{OD}_{620}$. The value obtained with $0.1 \% \mathrm{Na}_{2} \mathrm{CO}_{3}(\mathrm{w} / \mathrm{v})$ was considered as $100 \%$ hemolysis. $\mathrm{HC}_{50}$ is the protein required to produce $50 \%$ hemolysis.

\section{Isothermal titration calorimetry}

The interaction between SM:DOPC:Ch (1:1:1) 100-nm-diameter unilamellar vesicles and the Stnll variants was measured using a MicroCal VP-ITC MicroCalorimeter (Northampton, MA) in $10 \mathrm{mM}$ Tris buffer, $\mathrm{pH} 7.5$, containing $0.1 \mathrm{M} \mathrm{NaCl}$ and $1 \mathrm{mM}$ EDTA at $25^{\circ} \mathrm{C}$. To prepare the lipid vesicles, an appropriate volume of the lipids dissolved in (2:1) (v/v) chloroform/methanol was dried in a Univapo $100 \mathrm{H}$ system (Uniequip, Martinsried/Munich, Germany). Then, films were hydrated for 1 hour at $37^{\circ} \mathrm{C}$ in the buffer above. The suspension obtained was five times extruded through two stacked $0.1 \mu \mathrm{m}$ (pore diameter) Nucleopore filters (Whatman, Brentford, England) in a thermobarrel extruder (Lipex Bio-Membranes, Vancouver, Canada) at $37^{\circ} \mathrm{C}$. Vesicles were employed immediately after their preparation. Final lipid concentration was estimated from the phosphorous content of the samples ${ }^{41}$. To avoid any interference due to low-molecular weight solutes, proteins were dialyzed against the same buffer in which lipids were to be suspended. Immediately before starting the titration, samples were degasified in a ThermoVac (MicroCal, Northampton, MA). To perform the titration, $20-\mu L$-aliquots of the lipid suspension $\left(L_{0}\right.$ $=0.4-3 \mathrm{mM})$ were injected into the protein solution $\left(P_{0}=1-4 \mu \mathrm{M}\right)$, which was 
continuously stirred (300 rpm). The heat released in each injection was calculated from the raw data by integration of the peaks after subtraction of the baseline.

The binding isotherms were adjustable to a model in which a molecule of protein binds the membrane involving " $n$ " lipid molecules ${ }^{21}$. Then,

$$
\begin{array}{ll}
P+L^{\prime} \stackrel{K}{\longleftrightarrow} P L & \text { Equation [1] } \\
K=\frac{|P L|}{|P|^{\prime} L^{\prime} \mid} & \text { Equation [2] }
\end{array}
$$

where $[P L]$ and $[P]$ are the concentrations of bound and free protein, respectively, $K$ is the binding constant, and [' $L$ '] is the concentration of lipid accessible to bind a protein. At any time:

$$
\begin{array}{ll}
|P|=P_{T}-|P L| & \text { Equation [3] } \\
\left.\right|^{\prime} L\left|=\frac{L_{T}}{n}-\right| P L \mid & \text { Equation [4] }
\end{array}
$$

$P_{T}$ and $L_{T}$ correspond to the bulk protein and lipid concentrations, respectively. The combination of equations [2], [3] and [4] leads to equation [5]:

$$
\Theta^{2}-\Theta\left(1+\frac{L_{T}}{n \cdot P_{T}}+\frac{1}{K \cdot P_{T}}\right)+\frac{L_{T}}{n \cdot P_{T}}=0
$$

Equation [5]

where $\Theta$ is the fraction of bound protein. The total heat content $(Q)$ of the solution contained in the cell volume $\left(V_{o}\right)$ (considering that unbound species have heat content equal to zero) at fractional saturation $\Theta$ is:

$$
Q=\Theta \cdot P_{T} \cdot \Delta H \cdot V_{0} \quad \text { Equation [6] }
$$

Therefore, experimental data can be fitted to the combination of equations [5] and [6] to obtain $K, n$ and $\Delta H$, where $\Delta H$ is the change of enthalpy associated with 
binding in energy units per mol. Corrections for displaced volume effects were automatically made by Origin software (OriginLab, Northampton, MA) provided by MicroCal. Finally, changes in entropy $(\Delta S)$ and Gibbs free energy $(\Delta G)$ can be calculated according to equation [7], which takes into consideration the relationship between the equilibrium constant $K$ and the partition coefficient in terms of the reactant volumes ${ }^{42}$ :

$$
\Delta G=-R \cdot T \cdot \ln \left(\frac{K}{0.8 \cdot n}\right)=\Delta H-T \cdot \Delta S
$$

Equation [7]

0.8 being the specific lipid molar volume $(\mathrm{L} / \mathrm{mol})^{42}$.

\section{Acknowledgements}

We thank Dr. Erik Goormaghtigh (Free University of Brussels, Belgium) for providing us with the software employed to process infrared spectra and for his general advices regarding infrared spectroscopy. We are grateful to Dr. Gregor Anderluh (University of Ljubljana, Slovenia) for useful discussion about the results presented in this report. This work was supported by grant BFU2006-04404 from the Ministerio de Educación y Ciencia (Spain). J.A.-C. and E.H.-G were the recipients of a fellowship from the Ministerio de Educación y Ciencia (Spain).

\section{References}

1. Parker, M. W. \& Feil, S. C. (2005) Pore-forming protein toxins: from structure to function. Prog. Biophys. Mol. Biol. 88, 91-142.

2. Maček, P. (1992) Polypeptide cytolytic toxins from sea anemones (Actiniaria). FEMS Microbio.I Immunol. 5, 121-129.

3. Anderluh, G. \& Maček, P. (2002) Cytolytic peptide and protein toxins from sea anemones (Anthozoa: Actiniaria). Toxicon 40, 111-124.

4. Alegre-Cebollada, J., Oñaderra, M., Gavilanes, J. G. \& Martínez del Pozo, Á. (2007) Sea anemone actinoporins: the transition from a folded soluble state to 
a functionally active membrane-bound oligomeric pore. Curr. Protein Pept. Sci. 8, 558-572.

5. Athanasiadis, A., Anderluh, G., Maček, P. \& Turk, D. (2001) Crystal structure of the soluble form of equinatoxin II, a pore-forming toxin from the sea anemone Actinia equina. Structure 9, 341-346.

6. Hinds, M. G., Zhang, W., Anderluh, G., Hansen, P. E. \& Norton, R. S. (2002) Solution structure of the eukaryotic pore-forming cytolysin equinatoxin II: implications for pore formation. J. Mol. Biol. 315, 1219-1229.

7. Mancheño, J. M., Martín-Benito, J., Martínez-Ripoll, M., Gavilanes, J. G. \& Hermoso, J. A. (2003) Crystal and electron microscopy structures of sticholysin II actinoporin reveal insights into the mechanism of membrane pore formation. Structure 11, 1319-1328.

8. Malovrh, P., Viero, G., Dalla Serra, M., Podlesek, Z., Lakey, J. H., Maček, P., Menestrina, G. \& Anderluh, G. (2003) A novel mechanism of pore formation: membrane penetration by the $\mathrm{N}$-terminal amphipathic region of equinatoxin. $J$. Biol. Chem. 278, 22678-22685.

9. Alegre-Cebollada, J., Martínez del Pozo, Á., Gavilanes, J. G. \& Goormaghtigh, E. (2007) Infrared spectroscopy study on the conformational changes leading to pore formation of the toxin sticholysin II. Biophys. J. 93, 3191-3201.

10. Malovrh, P., Barlič, A., Podlesek, Z., Maček, P., Menestrina, G. \& Anderluh, G. (2000) Structure-function studies of tryptophan mutants of equinatoxin II, a sea anemone pore-forming protein. Biochem. J. 346, 223-232.

11. Hong, Q., Gutiérrez-Aguirre, I., Barlič, A., Malovrh, P., Kristan, K., Podlesek, Z., Maček, P., Turk, D., González-Mañas, J. M., Lakey, J. H. \& Anderluh, G. (2002) Two-step membrane binding by Equinatoxin II, a pore-forming toxin from the sea anemone, involves an exposed aromatic cluster and a flexible helix. J. Biol. Chem. 277, 41916-41924.

12. Mancheño, J. M., Martín-Benito, J., Gavilanes, J. G. \& Vázquez, L. (2006) A complementary microscopy analysis of Sticholysin II crystals on lipid films: Atomic force and transmission electron characterizations. Biophys. Chem. 119, 219-223

13. De los Ríos, V., Mancheño, J. M., Martínez del Pozo, Á., Alfonso, C., Rivas, G., Oñaderra, M. \& Gavilanes, J. G. (1999) Sticholysin II, a cytolysin from the 
sea anemone Stichodactyla helianthus, is a monomer-tetramer associating protein. FEBS Lett. 455, 27-30.

14. Anderluh, G., Barlič, A., Podlesek, Z., Maček, P., Pungerčar, J., Gubenšek, F., Zecchini, M. L., Dalla Serra, M. \& Menestrina, G. (1999) Cysteinescanning mutagenesis of an eukaryotic pore-forming toxin from sea anemone: topology in lipid membranes. Eur. J. Biochem. 263, 128-136.

15. Bakrač, B., Gutiérrez-Aguirre, I., Podlesek, Z., Sonnen, A. F., Gilbert, R. J., Maček, P., Lakey, J. H. \& Anderluh, G. (2008) J. Biol. Chem. In press.

16. Alegre-Cebollada, J., Lacadena, V., Oñaderra, M., Mancheño, J. M., Gavilanes, J. G., and Martínez del Pozo, Á. (2004) Phenotypic selection and characterization of randomly produced non-haemolytic mutants of the toxic sea anemone protein sticholysin II. FEBS Lett. 575, 14-18

17. Alegre-Cebollada, J., Clementi, G., Cunietti, M., Porres, C., Oñaderra, M., Gavilanes, J. G. \& Martínez del Pozo, Á. (2007) Silent mutations at the 5'-end of the cDNA of actinoporins from the sea anemone Stichodactyla helianthus allow their heterologous overproduction in Escherichia coli. J. Biotechnol. 127, 211-221.

18. Velázquez-Campoy, A., Ohtaka, H., Nezami, A., Muzammil, S. \& Freire, E. (2004) Isothermal titration calorimetry. Curr. Protoc. Cell. Biol., 17.18.1117.18.24.

19. Seelig, J. (2004) Thermodynamics of lipid-peptide interactions. Biochim. Biophys. Acta 1666, 40-50.

20. Alegre-Cebollada, J., Rodríguez-Crespo, I., Gavilanes, J. G. \& Martínez del Pozo, Á. (2006) Detergent-resistant membranes are platforms for actinoporin pore-forming activity on intact cells. FEBS J. 273, 863-871.

21. Gasset, M., Martínez del Pozo, Á., Oñaderra, M. \& Gavilanes, J. G. (1989) Study of the interaction between the antitumour protein $\alpha$-sarcin and phospholipid vesicles. Biochem. J. 258, 569-575

22. Guerrero-Valero, M., Marín-Vicente, C., Gómez-Fernández, J. C. \& CorbalánGarcía, S. (2007) The C2 domains of classical PKCs are specific Ptdlns(4,5)P2-sensing domains with different affinities for membrane binding. J. Mol. Biol. 371, 608-621.

23. Saito, H., Dhanasekaran, P., Nguyen, D., Deridder, E., Holvoet, P., LundKatz, S. \& Phillips, M. C. (2004) a-Helix formation is required for high affinity 
binding of human apolipoprotein A-I to lipids. J. Biol. Chem. 279, 2097420981.

24. Myszka, D. G., Sweet, R. W., Hensley, P., Brigham-Burke, M., Kwong, P. D., Hendrickson, W. A., Wyatt, R., Sodroski, J. \& Doyle, M. L. (2000) Energetics of the HIV gp120-CD4 binding reaction. Proc. Natl. Acad. Sci. U. S. A. 97 , 9026-9031.

25. Menestrina, G., Cabiaux, V. \& Tejuca, M. (1999) Secondary structure of sea anemone cytolysins in soluble and membrane bound form by infrared spectroscopy. Biochem. Biophys. Res. Commun. 254, 174-180.

26. Valcárcel, C. A., Dalla Serra, M., Potrich, C., Bernhart, I., Tejuca, M., Martínez, D., Pazos, F., Lanio, M. E. \& Menestrina, G. (2001) Effects of lipid composition on membrane permeabilization by sticholysin I and II, two cytolysins of the sea anemone Stichodactyla helianthus. Biophys. J. 80, 27612774.

27. Anderluh, G., Dalla Serra, M., Viero, G., Guella, G., Maček, P. \& Menestrina, G. (2003) Pore formation by equinatoxin II, a eukaryotic protein toxin, occurs by induction of nonlamellar lipid structures. J. Biol. Chem. 278, 45216-45223.

28. Varanda, W. \& Finkelstein, A. (1980) Ion and nonelectrolyte permeability properties of channels formed in planar lipid bilayer membranes by the cytolytic toxin from the sea anemone, Stoichactis helianthus. J. Membr. Biol. 55, 203-211.

29. Caaveiro, J. M., Echabe, I., Gutiérrez-Aguirre, I., Nieva, J. L., Arrondo, J. L. \& González-Mañas, J. M. (2001) Differential interaction of equinatoxin II with model membranes in response to lipid composition. Biophys. J. 80, 13431353.

30. Seelig, J. (1997) Titration calorimetry of lipid-peptide interactions. Biochim. Biophys. Acta 1331, 103-116.

31. Malham, R., Johnstone, S., Bingham, R. J., Barratt, E., Phillips, S. E. V., Laughton, C. A. \& Homans, S. W. (2005) Strong solute-solute dispersive interactions in a protein-ligand complex. J. Am. Chem. Soc. 127, 1706117067.

32. Leavitt, S. \& Freire, E. (2001) Direct measurement of protein binding energetics by isothermal titration calorimetry. Curr. Opin. Struct. Biol. 11, 560566. 
33. Barlič, A., Gutiérrez-Aguirre, I., Caaveiro, J. M., Cruz, A., Ruiz-Argüello, M. B., Pérez-Gil, J. \& González-Mañas, J. M. (2004) Lipid phase coexistence favors membrane insertion of equinatoxin-II, a pore-forming toxin from Actinia equina. J. Biol. Chem. 279, 34209-34216.

34. Wimley, W. C. \& White, S. H. (1996) Experimentally determined hydrophobicity scale for proteins at membrane interfaces. Nat. Struct. Biol. 3, 842-848.

35. De los Ríos, V., Mancheño, J. M., Lanio, M. E., Oñaderra, M. \& Gavilanes, J. G. (1998) Mechanism of the leakage induced on lipid model membranes by the hemolytic protein sticholysin II from the sea anemone Stichodactyla helianthus. Eur. J. Biochem. 252, 284-289.

36. Kristan, K., Podlesek, Z., Hojnik, V., Gutiérrez-Aguirre, I., Gunčar, G., Turk, D., González-Mañas, J. M., Lakey, J. H., Maček, P. \& Anderluh, G. (2004) Pore formation by equinatoxin, a eukaryotic pore-forming toxin, requires a flexible N-terminal region and a stable $\beta$-sandwich. J. Biol. Chem. 279, 4650946517

37. Wieprecht, T., Beyermann, M. \& Seelig, J. (2002) Thermodynamics of the coil-alpha-helix transition of amphipathic peptides in a membrane environment: the role of vesicle curvature. Biophys. Chem. 96, 191-201

38. Sambrook, J. \& Russell, D. W. (2001) Molecular Cloning: A Laboratory Manual, Cold Spring Harbor Laboratory Press, Cold Spring Harbor, NY

39. Mancheño, J. M., De los Ríos, V., Martínez del Pozo, Á., Lanio, M. E., Oñaderra, M. \& Gavilanes, J. G. (2001) Partially folded states of the cytolytic protein sticholysin II. Biochim. Biophys. Acta 1545, 122-131.

40. Goormaghtigh, E., Raussens, V. \& Ruysschaert, J. M. (1999) Attenuated total reflection infrared spectroscopy of proteins and lipids in biological membranes. Biochim. Biophys. Acta 1422, 105-185.

41. Bartlett, G. R. (1959) Phosphorus assay in column chromatography. J. Biol. Chem. 234, 466-468.

42. Heymann, J. B., Zakharov, S. D., Zhang, Y. L., and Cramer, W. A. (1996) Characterization of electrostatic and nonelectrostatic components of proteinmembrane binding interactions. Biochemistry 35, 2717-2725.

43. Humphrey, W., Dalke, A. \& Schulten, K. (1996) VMD: visual molecular dynamics. J. Mol. Graph. 14, 33-38, 27-38. 


\section{Figure legends}

Fig. 1. (A) Three-dimensional representation of the water-soluble state of Stnll (PDB code $1 \mathrm{GWY}$ ). Residues mutated in this study are highlighted. The N-terminus position is indicated. Figure was generated with $\mathrm{VMD}^{43}$. (B) Scheme of the putative model of pore formation by actinoporins. $S$ : water-soluble state. $\mathrm{M}_{\mathrm{o}}$ : monomeric membrane-bound form. $\mathrm{M}_{1}$ and $\mathrm{M}_{2}$ : tetrameric membrane-bound forms with no conductive properties. P: pore state. For the sake of simplicity, only three monomers are represented in $M_{1}, M_{2}$ and $P$ states.

Fig. 2. CD-spectra in the near-UV region. Vertical bars show the ellipticity range where the spectra of all purified mutants are included. Dashed line corresponds to the near-UV spectrum of $\mathrm{Y} 111 \mathrm{~N}$ variant.

Fig. 3. Thermal denaturation profiles for wild-type Stnll (triangles), R29Q (solid circles, top), A10P/S28P (open circles, top), F106L (solid squares, top), S28P (open squares, top), K19E/E23K (solid circles, bottom), A10P (open circles, bottom), Y111N (open squares, bottom) and K19E (solid squares, bottom).

Fig. 4. Hemolytic activities of Stnll mutants. Inverse $\mathrm{HC}_{50}$ values (concentration required for $50 \%$ hemolysis) are given. Three different determinations were averaged. Error bars represent standard deviations.

Fig. 5. Binding of Stnll and its mutants to SM:DOPC:Ch (1:1:1) 100-nm-diameter vesicles studied by ITC. Reactants concentrations were: $\mathrm{WT}\left(\mathrm{P}_{0}=1.2 \mu \mathrm{M}, \mathrm{L}_{0}=0.56\right.$ $\mathrm{mM}), \mathrm{A} 10 \mathrm{P}\left(\mathrm{P}_{0}=1.1 \mu \mathrm{M}, \mathrm{L}_{0}=0.55 \mathrm{mM}\right), \mathrm{K} 19 \mathrm{E}\left(\mathrm{P}_{0}=1.4 \mu \mathrm{M}, \mathrm{L}_{0}=0.65 \mathrm{mM}\right), \mathrm{S} 28 \mathrm{P}$ $\left(P_{0}=1.3 \mu \mathrm{M}, L_{0}=0.81 \mathrm{mM}\right), \mathrm{R} 29 \mathrm{Q}\left(\mathrm{P}_{0}=2.3 \mu \mathrm{M}, \mathrm{L}_{0}=1.8 \mathrm{mM}\right), \mathrm{F} 106 \mathrm{~L}\left(\mathrm{P}_{0}=1.1 \mu \mathrm{M}\right.$, $\left.\mathrm{L}_{0}=0.53 \mathrm{mM}\right), \mathrm{Y} 111 \mathrm{~N}\left(\mathrm{P}_{0}=1.2 \mu \mathrm{M}, \mathrm{L}_{0}=1.6 \mathrm{mM}\right), \mathrm{A} 10 \mathrm{P} / \mathrm{S} 28 \mathrm{P}\left(\mathrm{P}_{0}=1.1 \mu \mathrm{M}, \mathrm{L}_{0}=\right.$ $0.73 \mathrm{mM}), \mathrm{K} 19 \mathrm{E} / \mathrm{E} 23 \mathrm{~K}\left(\mathrm{P}_{0}=1.2 \mu \mathrm{M}, \mathrm{L}_{0}=0.72 \mathrm{mM}\right)$. Binding isotherms were adjusted to a model in which the protein binds the membrane involving $n$ lipid molecules. The $c$ values $\left(c=K \times P_{0}\right)$ for all the graphs are in the range 1-1000.

Fig. 6. (A) Infrared spectra of Stnll WT (solid) and A10P/S28P (dashed) in the presence of SM:DOPC:Ch (1:1:1) membranes. Lipid contribution was subtracted by 
using the lipid band area $\left(1762-1716 \mathrm{~cm}^{-1}\right)$ to normalize. (B) $\alpha$-Helix formation upon lipid binding of Stnll and its mutants. Values represent the relative (proteinlipid) to (protein) variations of the infrared absorbance at 1658 and $1638 \mathrm{~cm}^{-1}$ ratio (see text). After removal of lipid contribution, a linear baseline between 1708 and $1490 \mathrm{~cm}^{-1}$ was subtracted. Three independent determinations were averaged. Error bars indicate standard deviations. 
Table. 1 Purification and characterization of Stnll mutants.

\begin{tabular}{|c|c|c|c|c|}
\hline Protein & $\begin{array}{l}\text { Yield (mg per liter of } \\
\text { culture) }\end{array}$ & $\begin{array}{l}\mathrm{T}_{\mathrm{m}} \\
\left({ }^{\circ} \mathrm{C}\right)\end{array}$ & $\begin{array}{c}E(0.1 \%, 1 \mathrm{~cm}, 280 \\
\mathrm{nm})\end{array}$ & $\begin{array}{l}\mathrm{HC}_{50} \\
\text { (nM) }\end{array}$ \\
\hline Stnll WT & 5.0 & 67 & 2.54 & 1.4 \\
\hline A10P & 5.7 & 66 & 2.69 & 5.3 \\
\hline K19E & 4.5 & 68 & 2.48 & 4.2 \\
\hline S28P & 6.1 & 66 & 2.71 & 2.2 \\
\hline R29Q & 4.9 & 60 & 2.54 & 50.9 \\
\hline F106L & 0.85 & 66 & 2.62 & 3.6 \\
\hline Y111N & 2.1 & 70 & 2.58 & 231 \\
\hline A10P/S28P & 8.0 & 63 & 2.50 & 35 \\
\hline K19E/E23K & 6.3 & 59 & 2.60 & 1.1 \\
\hline
\end{tabular}


Table 2. Binding to SM:DOPC:Ch (1:1:1) vesicles by Stnll and its mutants studied by ITC. Results are the mean of at least two independent determinations.

Standard deviations are indicated.

\begin{tabular}{|c|c|c|c|c|c|c|c|}
\hline Stn II & $n$ & $\begin{array}{c}K \times 10^{-8} \\
\left(M^{-1}\right)\end{array}$ & $\begin{array}{c}\Delta G \\
(\mathrm{Kcal} / \\
\mathrm{mol})\end{array}$ & $\begin{array}{c}\Delta H \\
\text { (Kcal/ } \\
\text { mol) }\end{array}$ & $\begin{array}{c}\Delta S(\mathrm{cal} / \\
\mathrm{mol} / \mathrm{K})\end{array}$ & $\begin{array}{c}\text { Relative } \\
\text { hemolytic } \\
\text { activity* }\end{array}$ & $\begin{array}{c}\text { Relative } \\
\text { membrane } \\
\text { binding }\end{array}$ \\
\hline WT & $39 \pm 4$ & $1.7 \pm 0.9$ & $-9.1 \pm 0.5$ & $-44 \pm 3$ & $-115 \pm 9$ & 1.0 & 1.0 \\
\hline A10P & $37 \pm 4$ & $1.9 \pm 0.9$ & $-9.3 \pm 0.4$ & $-39 \pm 6$ & $-99 \pm 20$ & 0.26 & 1.18 \\
\hline K19E & $34 \pm 1$ & $0.9 \pm 0.3$ & $-8.9 \pm 0.3$ & $-34 \pm 2$ & $-86 \pm 6$ & 0.33 & 0.61 \\
\hline S28P & $48 \pm 1$ & $1.3 \pm 0.4$ & $-8.9 \pm 0.2$ & $-47 \pm 4$ & $\begin{array}{c}-129 \pm \\
14\end{array}$ & 0.64 & 0.62 \\
\hline R29Q & $51 \pm 8$ & $\begin{array}{l}0.031 \pm \\
0.002\end{array}$ & $-6.7 \pm 0.2$ & $-45 \pm 3$ & $-129 \pm 8$ & 0.028 & 0.014 \\
\hline F106L & $36 \pm 3$ & $0.6 \pm 0.1$ & $-8.6 \pm 0.1$ & $-37 \pm 7$ & $-94 \pm 24$ & 0.39 & 0.38 \\
\hline Y111N & $46 \pm 7$ & $\begin{array}{l}0.025 \pm \\
0.004\end{array}$ & $-6.6 \pm 0.1$ & $-47 \pm 2$ & $-134 \pm 4$ & 0.006 & 0.012 \\
\hline $\begin{array}{l}\text { A10PI } \\
\text { S28P }\end{array}$ & $43 \pm 5$ & $2.4 \pm 0.8$ & $-9.3 \pm 0.2$ & $-32 \pm 3$ & $-78 \pm 8$ & 0.04 & 1.28 \\
\hline $\begin{array}{l}\text { K19E/ } \\
\text { E23K }\end{array}$ & $44 \pm 4$ & $1.6 \pm 1.0$ & $-8.9 \pm 0.6$ & $-45 \pm 6$ & $\begin{array}{c}-119 \pm \\
20\end{array}$ & 1.27 & 0.83 \\
\hline \multicolumn{8}{|c|}{$\begin{array}{l}{ }^{*} \text { Relative hemolytic activity }=\frac{H C_{50}(W T)}{H C_{50}(m u t)} \\
{ }^{* *} \text { Relative membrane binding }=\frac{n(W T) \cdot K(m u t)}{n(m u t) \cdot K(W T)}\end{array}$} \\
\hline
\end{tabular}


(this approximation is valid if $L_{T}$ is in excess with respect to $P_{T}$ and $L_{T} \ll n / K$ ) 
Table 3. Molecular orientation of lipid acyl chains.

The angles of the lipid acyl chains with respect to the normal of the Ge plate were calculated as described before ${ }^{9,40}$. Mean values of three independent determinations are averaged. Standard deviations were below $3^{\circ}$.

\begin{tabular}{ccc}
\cline { 2 - 3 } & \multicolumn{2}{c}{ Band } \\
Sample & $\mathbf{V}_{\text {as }}\left(\mathbf{C H}_{\mathbf{2}}\right)$ & $\mathbf{V}_{\mathbf{s}}\left(\mathbf{C H}_{\mathbf{2}}\right)$ \\
& $\left(\mathbf{2 9 3 0}-\mathbf{2 9 0 0 \mathbf { ~ c m } ^ { - 1 } )}\right.$ & $\left(\mathbf{2 8 5 8}-\mathbf{2 8 3 8} \mathbf{~ c m}^{-1}\right)$ \\
\hline Lipids & $38^{\circ}$ & $41^{\circ}$ \\
Lipids + WT & $42^{\circ}$ & $45^{\circ}$ \\
Lipids + A10P & $40^{\circ}$ & $43^{\circ}$ \\
Lipids + K19E & $40^{\circ}$ & $43^{\circ}$ \\
Lipids + S28P & $40^{\circ}$ & $42^{\circ}$ \\
Lipids + R29Q & $41^{\circ}$ & $44^{\circ}$ \\
Lipids + F106L & $39^{\circ}$ & $43^{\circ}$ \\
Lipids + Y111N & $38^{\circ}$ & $41^{\circ}$ \\
Lipids + A10P/S28P & $41^{\circ}$ & $44^{\circ}$ \\
Lipids + K19E/E23K & $43^{\circ}$ & $44^{\circ}$ \\
\hline
\end{tabular}




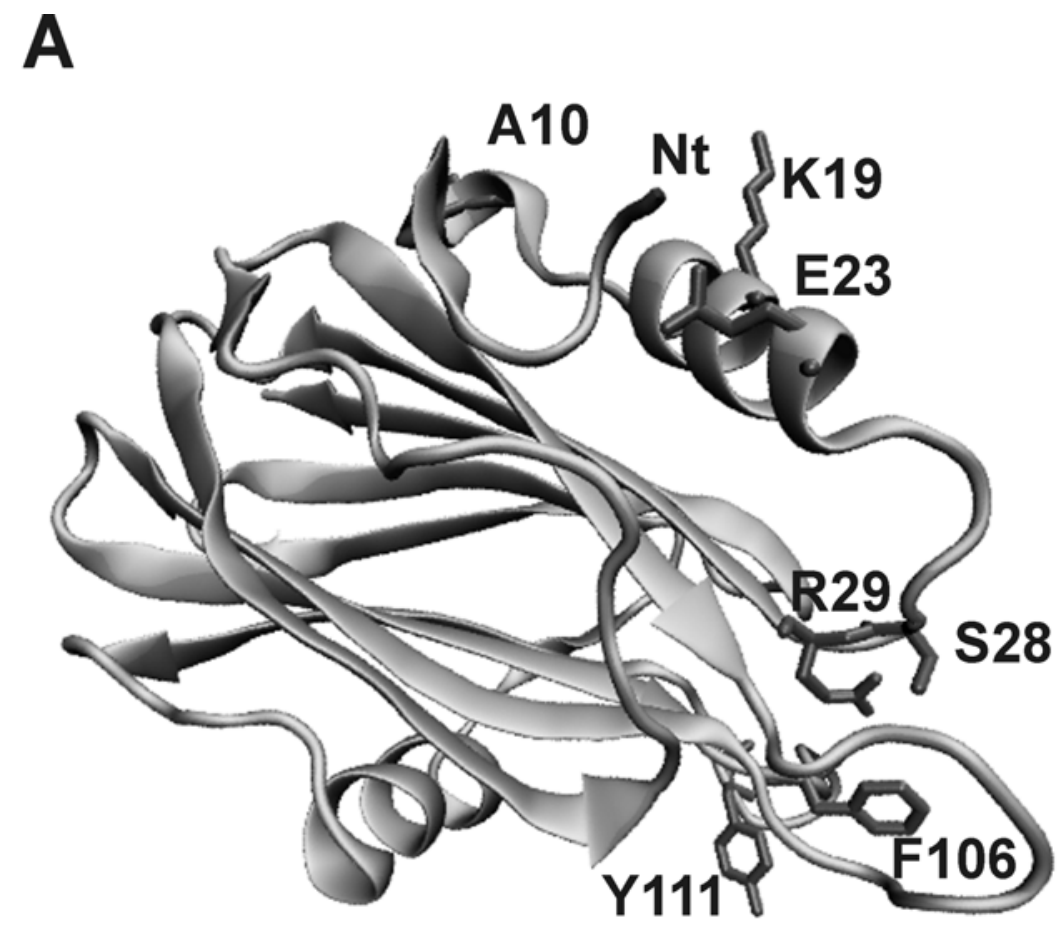

B

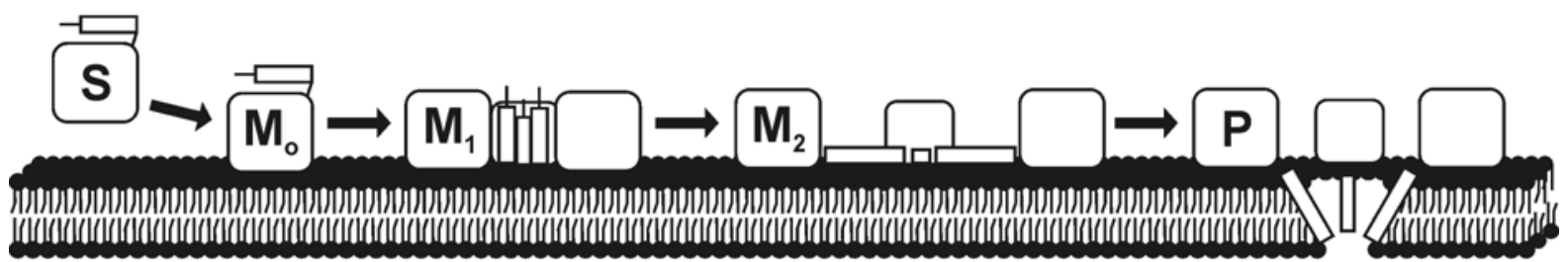

Figure 1 


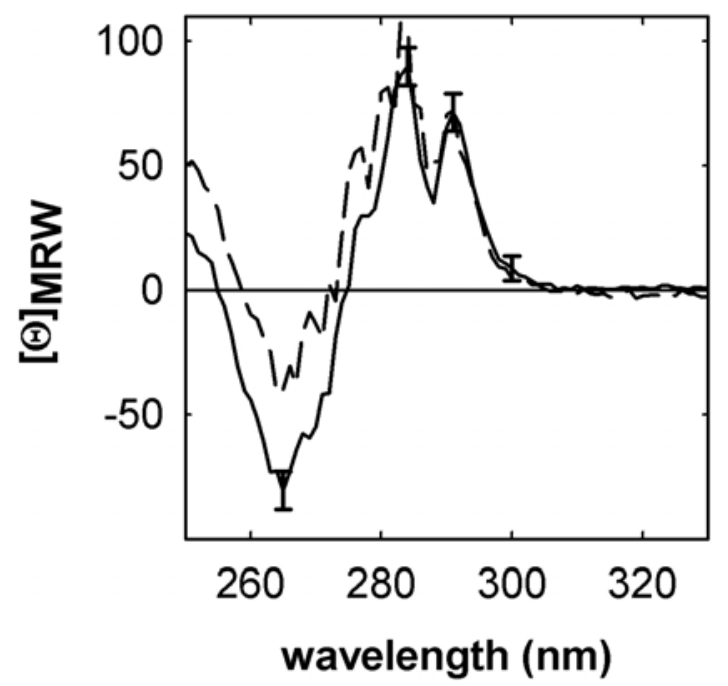

Figure 2 


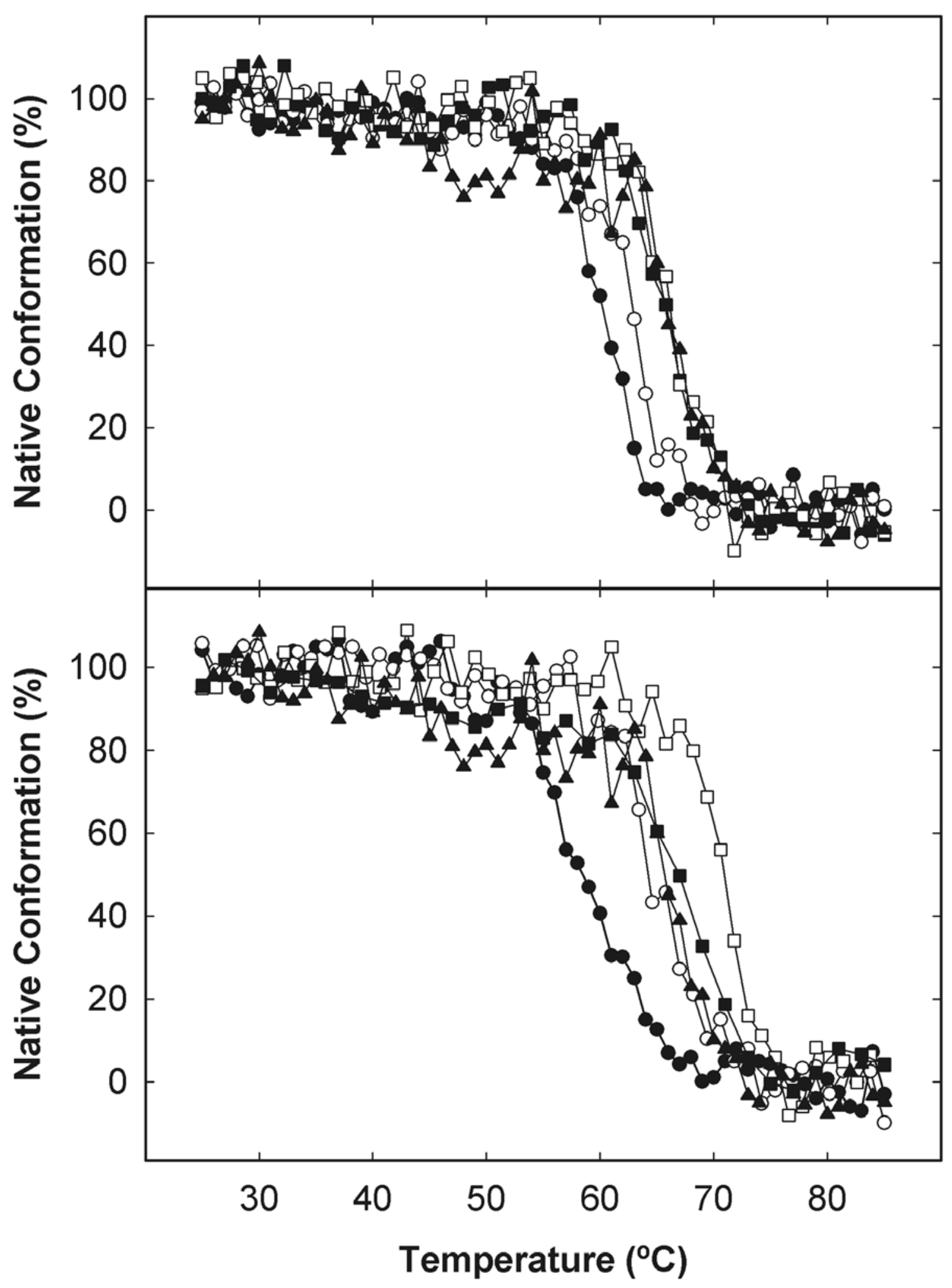

Figure 3 


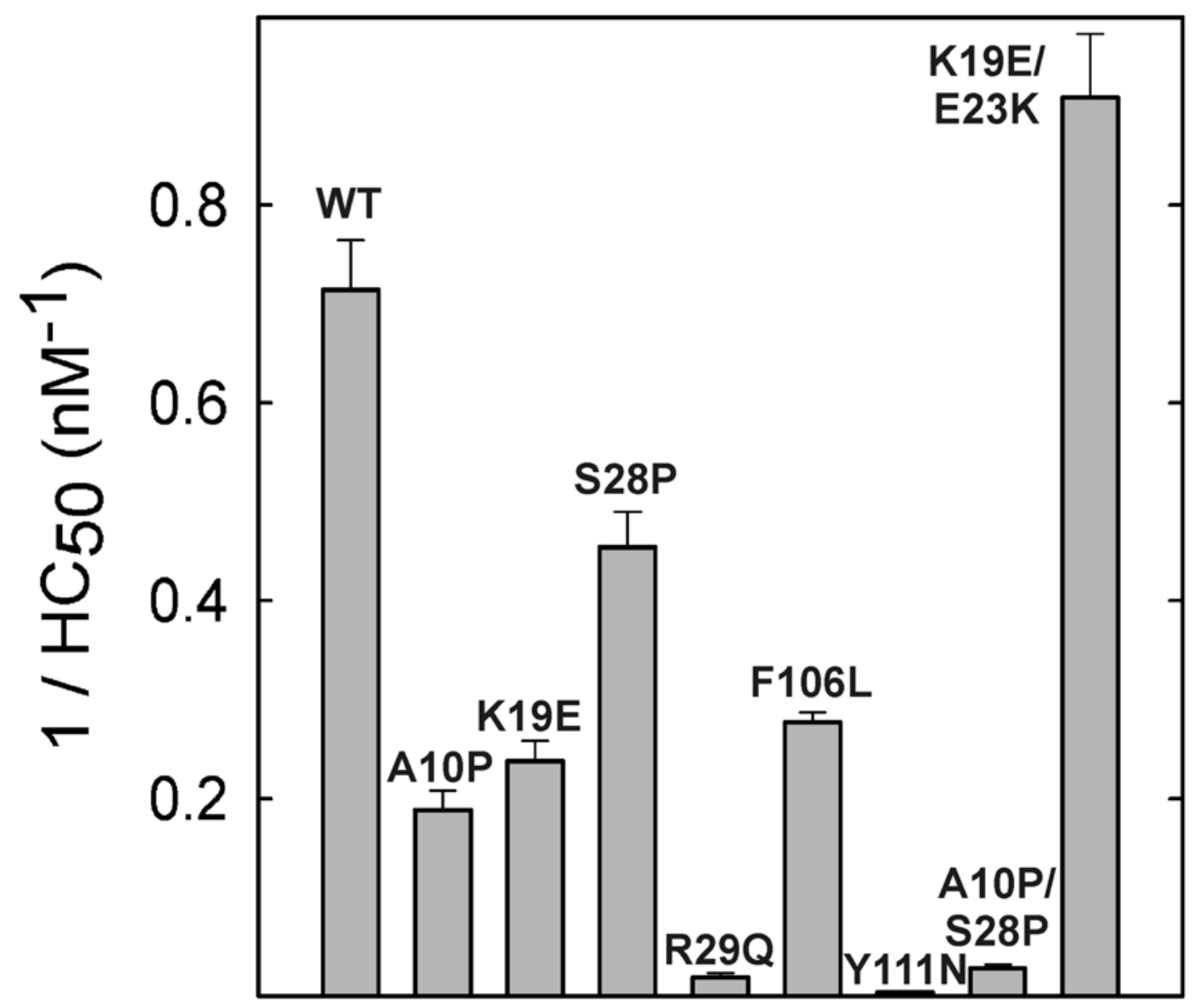

Figure 4 

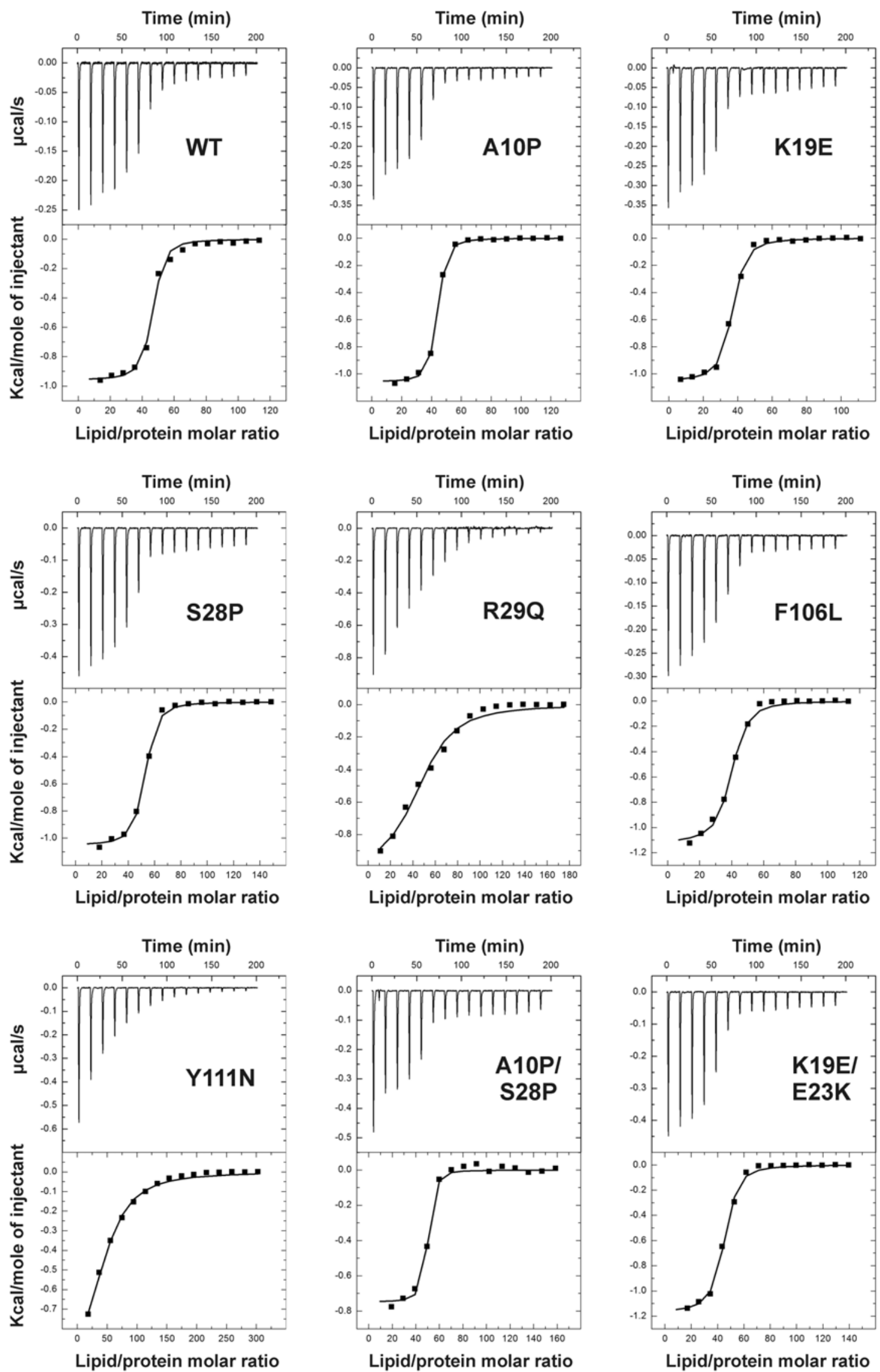

Figure 5 

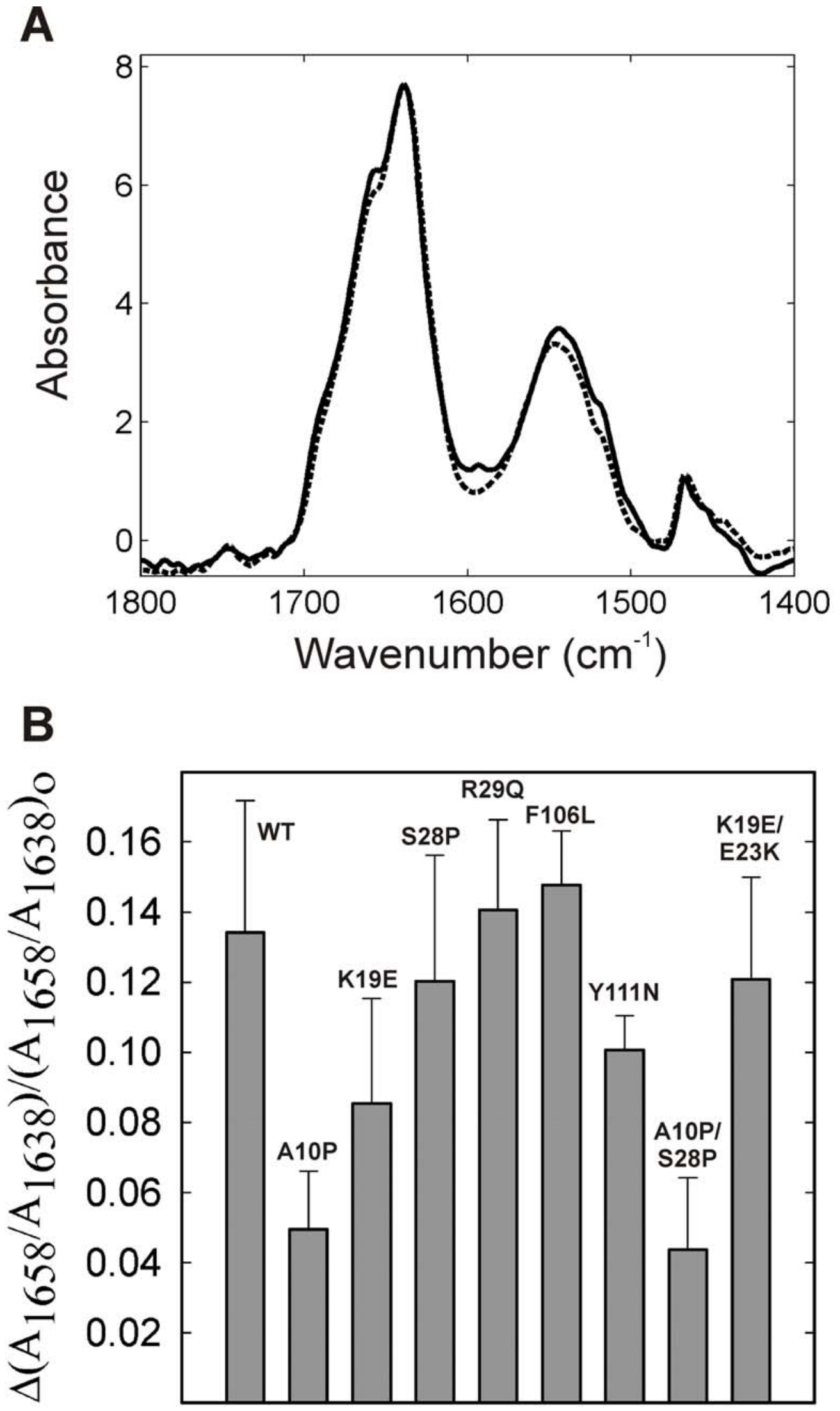

Figure 6 